\title{
Studies on the Mechanism of Potassium-stimulated Respiration in Escherichia coli
}

\author{
By SHUNAMITH MILLER AND Y. AVI-DOR \\ The Israel Institute for Biological Research, Ness-Ziona, \\ AND J. MAGER \\ Cellular Biochemistry Research Unit, Department of Biochemistry, The Hebrew \\ University-Hadassah Medical School and School of Dentistry, Jerusalem
}

(Received 3 February 1964)

\begin{abstract}
SUMMARY
The inter-relationship between the intracellular concentration of potassium ions and the rate of oxidation of glutamate was investigated in washed Escherichia coli. The time-curve of glutamate oxidation by the potassiumdepleted coli showed a marked lag phase and the rate of oxygen uptake increased concurrently with the accumulation of potassium ions. After a constant intracellular potassium concentration was reached, the rate of oxidation remained constant. Carbonyl cyanide $m$-chlorophenylhydrazone ( $m$-Cl-CCP) and methylene blue inhibited the respiration when added to the reaction mixture during the initial phase of $\mathbf{K}^{+}$accumulation. The extent of inhibition induced by these compounds was inversely related to the rate of oxidation prevailing at the time of their addition. No inhibition resulted when the substances were added after the $\mathrm{K}^{+}$accumulation and respiratory rate had reached the steady state values. Pre-incubation with glucose and $\mathrm{KCl}$ abolished the initial lag of glutamate oxidation as well as the inhibitory action of $m$-Cl-CCP. It is concluded that the intracellular concentration rather than the flux of potassium ion governs the control of respiration in $E$. coli. The possible relation of the mode of respiratory inhibition induced by $m$-Cl-CCP and methylene blue to the known ability of these compounds to uncouple oxidative phosphorylation, is discussed in terms of the presumed energy requirements of the system mediating the $\mathrm{K}^{+}$transport.
\end{abstract}

\section{INTRODUCTION}

An enhancing effect of potassium ions on bacterial respiration has been reported by several investigators (Quastel \& Webley, 1942; Krebs, Whittam \& Hems, 1957; Miller \& Avi-Dor, 1958). The potassium-stimulated respiration was found to be attended by an accumulation of potassium ions in the bacteria (Krebs et al. 1957). However, the question of whether the rate of oxidation of the various substrates is governed by the flux of ions (see Whittam, 1961) or by the size of the intracellular $\mathrm{K}^{+}$pool (see Krebs et al. 1957; Hems \& Krebs, 1962) remains as yet unsettled. The present paper is concerned with some aspects of the mechanism of potassium accumulation and the relationship between the intracellular concentration of potassium and the respiratory activity of the bacteria. 


\section{METHODS}

Chemicals. The chemicals were obtained from the following sources. L-glutamic acid (Merck A. G., Darmstadt); succinic acid (Hopkin \& Williams Ltd.); the solutions of the free acids were adjusted to $\mathrm{pH} \mathbf{7 \cdot 2}$ by adding suitable amounts of tris buffer. Carbonyl cyanide $m$-chlorophenylhydrazone ( $m$-Cl-CCP) was generously supplied by Dr P. G. Heytler (E. I. Du Pont de Nemours and Co.). Uniformly labelled $\left({ }^{14} \mathrm{C}\right)$ glutamic acid (specific activity: 24 $\mu \mathrm{c} . / \mathrm{mg}$.) from the Radiochemical Centre, Amersham, Buckinghamshire. Cab-O-Sil gelatinizing agent was obtained from the Packard Instrument Co. (LaGrange, Illinois, U.S.A.).

Bacterial suspensions. Escherichia coli strain в was used throughout. Unless otherwise specified, the organism was grown on Difco nutrient agar. In some experiments the organism was grown on the minimal medium of Davis \& Mingioli (1950) in which, however, glucose was replaced by succinate or glutamate $(0.4 \%$, $\mathrm{w} / \mathrm{v}$ ) as carbon source. Following incubation at $37^{\circ}$ for $24 \mathrm{hr}$ the bacteria were harvested and washed three times with ice-cold redistilled water. The centrifugations were carried out for $10 \mathrm{~min}$. at $12,000 \mathrm{~g}$ at a temperature near $0^{\circ}$. The washed organisms were suspended in $\mathbf{0 . 2 5} \mathrm{M}$-sucrose solution to a final concentration equivalent to $50 \mathrm{mg}$. wet wt. $/ \mathrm{ml}$.

Analytical methods. To determine the concentration of intracellular potassium a sample of the bacterial suspension was centrifuged for $15 \mathrm{~min}$. at $12,000 \mathrm{~g}$ and the organisms washed once with the original volume of $0.25 \mathrm{M}$-sucrose. Acid-digestion and flame photometric determination of potassium were then performed as described by Krebs et al. (1957).

Oxygen uptake was measured by the conventional manometric method. For measuring $\left({ }^{14} \mathrm{C}\right) \mathrm{CO}_{2}$ production from labelled substrates, the respiratory $\mathrm{CO}_{2}$ was trapped by $\mathrm{KOH}$-moistened filter paper placed in the centre well of the Warburg flask and radioactivity was counted in a toluene-ethanol scintillator solution according to Buhler (1962). For measuring the radioactivity incorporated into the bacteria, a sample of the suspension was washed as described above for the determination of potassium. The bacteria were then resuspended in $0.5 \mathrm{ml}$. water and added to $10 \mathrm{ml}$. of Bray's scintillator solution (Bray, 1960) gelatinized with Cab-OSil thixotropic gel $(4 \%, w / v)$. Radioactivity was measured in a Tri-Carb Model 314 F liquid scintillation counter of the Packard Instrument Company.

\section{RESULTS}

\section{Stimulatory effect of potassium ions on respiration}

In a previous communication (Miller \& Avi-Dor, 1958) potassium ions were found to stimulate the oxidation of glutamate and glucose by washed Escherichia coli. It may be seen from Table 1 that the oxidation rate of several other substrates was also substantially accelerated by $\mathbf{K}^{+}$. The magnitude of the effect, however, varied with the different substrates, when tested under standard conditions involving three successive washings of the bacteria. While this treatment was usually sufficient to render the oxidation of glutamate strictly dependent on added $\mathbf{K}^{+}$, the oxidation of other substrates, in particular of succinate, proceeded at an appreciable rate without added $\mathrm{K}^{+}$. However, on increasing the number of washings the 
effect of $\mathrm{K}^{+}$on succinate oxidation became increasingly prominent. Since the $\mathbf{K}^{+}$ requirement for glutamate oxidation was the most readily shown, the latter substrate was used in most of the experiments to be described.

\title{
Table 1. Stimulation by potassium chloride of the oxidation of various substrates by Escherichia coli
}

\begin{abstract}
Each Warburg flask contained $50 \mathrm{~mm}$-tris buffer (pH 7.2), 3.3 $\mathrm{mm}$ of the respective substrate, $15 \mathrm{mg}$. wet wt. washed $E$. coli, and $3.3 \mathrm{mM} \mathrm{KCl}$ when indicated. Acetate and pyruvate were added as sodium salts. The solutions of succinic and glutamic acid were adjusted to $\mathrm{pH} \boldsymbol{\gamma \cdot 2}$ by adding suitable amounts of tris buffer (free base). Total volume: $3 \mathrm{ml}$. Incubation temperature: $\mathbf{2 8}^{\circ}$.
\end{abstract}

$\begin{array}{lcc}\text { Substrate } & \text { KCl omitted } & \text { KCl added } \\ \text { None } & \mathbf{0} & \mathbf{6} \\ \text { L-Glutamate } & \mathbf{1 2} & \mathbf{1 6 0} \\ \text { Succinate } & \mathbf{9 0} & \mathbf{1 2 0} \\ \text { Acetate } & \mathbf{6 0} & \mathbf{1 6 0} \\ \text { Pyruvate } & 40 & \mathbf{1 4 0} \\ \text { D-Glucose } & 80 & \mathbf{1 7 0}\end{array}$

To explore the correlation between $\mathrm{K}^{+}$accumulation and respiratory activity, washed Escherichia coli was incubated in Warburg flasks in the presence of glutamate and graded amounts of $\mathrm{KCl}$. The rate of oxygen uptake was recorded and at the end of a $60 \mathrm{~min}$. incubation period the intracellular $\mathrm{K}^{+}$concentration was determined. As shown in Fig. 1, both the intracellular $\mathrm{K}^{+}$and the oxidation rate increased in a nearly parallel fashion with increasing concentrations of $\mathrm{KCl}$ in the medium. At $3 \mathrm{~mm}-\mathrm{KCl}$ the rate of oxygen uptake reached its maximum value and the curve representing intracellular $\mathrm{K}^{+}$started to level off.

Figure 2 illustrates a kinetic experiment in which the time-curves of $\mathbf{K}^{+}$accumulation and of oxygen uptake were compared. It can be seen that, apart from a small amount of $\mathrm{K}^{+}$which entered the organisms instantaneously, there was very little accumulation of $\mathrm{K}^{+}$in the organisms during the first $10 \mathrm{~min}$. of incubation. This initial lag was followed by a phase of rapid increase in intracellular $\mathbf{K}^{+}$, approaching a constant value after $30 \mathrm{~min}$. of incubation. The oxygen uptake exhibited a similar course of gradual increase until a steady state was attained which closely coincided with the time the intracellular $\mathbf{K}^{+}$concentration reached a plateau.

The observed correlation between the intracellular $\mathrm{K}^{+}$concentration and the oxidation rate was further corroborated by the results summarized in Table 2 . In this experiment washed Escherichia coli organisms were enriched in $\mathbf{K}^{+}$by previous incubation in the presence of glutamate $+\mathrm{KCl}$, followed by washing with $\mathbf{0 . 2 5} \mathrm{M}$ sucrose solution. The organisms so treated, when transferred to fresh medium containing no $\mathrm{KCl}$, continued to oxidize glutamate at a rate amounting to about $70 \%$ of that observed in the presence of added $\mathrm{K}^{+}$. Control organisms which had been pre-incubated with $\mathrm{KCl}$ but without glutamate showed no detectable respiration. Furthermore, when the potassium-enriched organisms were incubated in the absence of an energy-yielding substrate, their intracellular $\mathbf{K}^{+}$pool rapidly became exhausted by diffusion into the surrounding medium. 


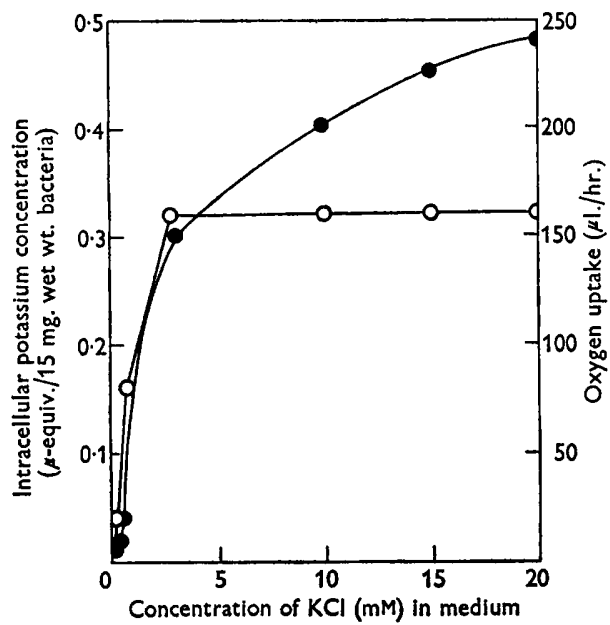

Fig. 1

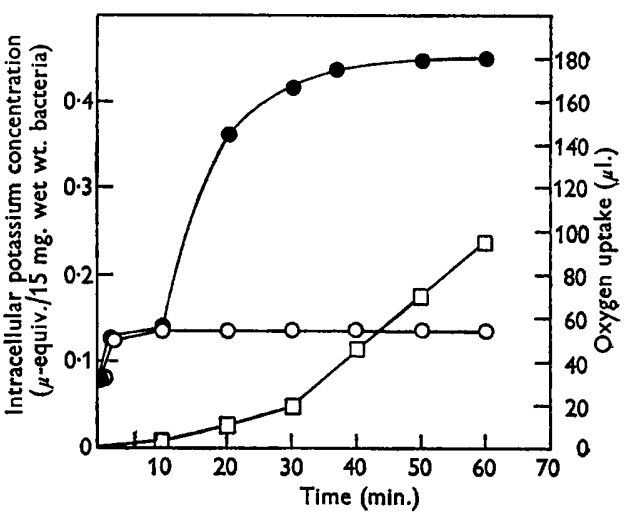

Fig. 2

Fig. 1. Effect of $\mathrm{KCl}$ concentration in the medium on the intracellular accumulation of potassium and glutamate oxidation. Each Warburg flask contained $50 \mathrm{~mm}$-tris buffer chloride (pH 7.2), 3.3 mM-glutamate, $15 \mathrm{mg}$. wet wt. washed bacteria and $\mathrm{KCl}$ as indicated. Total volume: $3.0 \mathrm{ml}$. Incubation: $60 \mathrm{~min}$. at $28^{\circ}$. At the end of incubation intracellular potassium was determined as described under Methods. $O$, Rate of oxygen uptake; $\boldsymbol{O}$, concentration of intracellular potassium.

Fig. 2. Time-course of oxygen uptake and of intracellular accumulation of potassium. Each Warburg flask contained 50 mM-tris buffer (pH 7.2), 3.3 mM-KCl, 15 mg. wet wt. washed bacteria and $\mathbf{3 . 3}$ mm-glutamate when indicated. Total volume $3.0 \mathrm{ml}$. Other conditions as in Fig. 1. O, Intracellular potassium in the absence of glutamate; $\bullet$, intracellular potassium in the presence of glutamate; $\square$, oxygen uptake.

\section{Table 2. Effect of the intracellular potassium concentration on the rate of glutamate oxidation by Escherichia coli}

Pre-treatments. Washed bacteria were incubated with shaking at $28^{\circ}$ for 60 min. with $\mathrm{KCl}$ alone (A) or with $\mathbf{3} \cdot 3 \mathrm{~mm}$-glutamate $+\mathrm{KCl}(\mathrm{B})$. The pretreated bacteria were separated by centrifugation $(20 \mathrm{~min}$. at $12,000 \mathrm{~g}$ ), and washed once with $0.25 \mathrm{M}$-sucrose. The final resuspension was made up in $0.25 \mathrm{M}$-sucrose. At the end of the 'pretreatment' the bacterial suspensions $A$ and $B$ contained 0.1 and $0.4 \mu$-equiv. potassium, respectively, per $15 \mathrm{mg}$. bacterial wet wt.

Assay. To each Warburg flask containing 50 mm-tris buffer ( $\mathrm{pH} \mathrm{7 \cdot 2)}$ and $\mathbf{3 \cdot 3} \mathrm{mm}-\mathrm{KCl}$ and/or $3.3 \mathrm{~mm}$-glutamate as indicated, $15 \mathrm{mg}$. wet wt. bacteria of the suspension (A) or (B) were added; total volume $3.0 \mathrm{ml}$. Incubation was carried out for $60 \mathrm{~min}$. at $28^{\circ}$. Oxygen uptake was recorded every $10 \mathrm{~min}$. At the end of the incubation the potassium content of the bacteria was determined as described under Methods.

Additions to the reaction

Bacterial suspension

A

B mixture

$\begin{array}{cc}\text { Glutamate } & \text { KCl } \\ \text { None } & \text { None } \\ + & \text { None } \\ + & + \\ \text { None } & \text { None } \\ + & \text { None } \\ + & +\end{array}$

Potassium content at the end of the assay ( $\mu$-equiv. $115 \mathrm{mg}$. wet. wt.) uptake ( $\mu \mathrm{l} . / \mathrm{hr})$

$$
0
$$$$
0.06
$$$$
0 \cdot 12
$$$$
0 \cdot 35
$$$$
\text { 0.04 }
$$$$
0 \cdot 40
$$$$
0.44
$$ 
It seemed of interest to test whether oxidation of glutamate would start without any lag in $\mathbf{K}^{+}$-rich organisms. For this purpose organisms were pre-incubated with $\mathrm{KCl}+$ glucose (the latter compound served as energy source for $\mathbf{K}^{+}$accumulation). Organisms incubated with $\mathrm{KCl}$ alone served as controls. Following pre-incubation, $\left({ }^{14} \mathrm{C}\right)$-labelled glutamate was added and the time-course of $\left({ }^{14} \mathrm{C}\right) \mathrm{CO}_{2}$ liberation and of glutamate uptake (in terms of radioactivity incorporated into the cell mass) was followed. The organisms which respired in the presence of glucose $+\mathrm{KCl}$ were found to contain $0 \cdot 40 \mu$-equiv. $\mathrm{K}^{+} / 15 \mathrm{mg}$. wet wt. at the time glutamate was added and showed practically no delay in the liberation of $\left({ }^{14} \mathrm{C}\right) \mathrm{CO}_{2}$. This behaviour con-

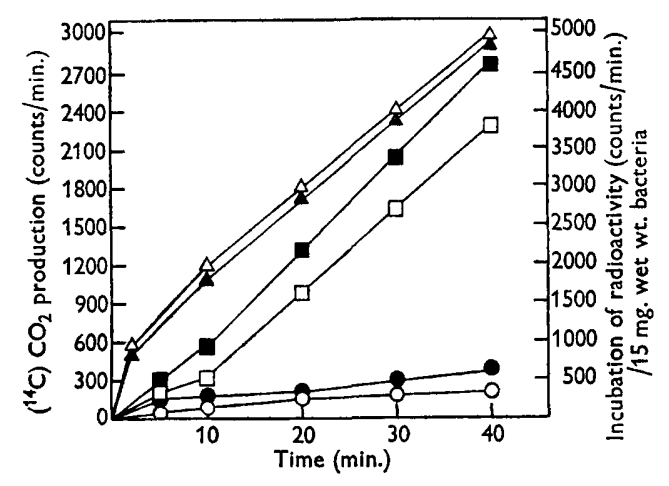

Fig. 3

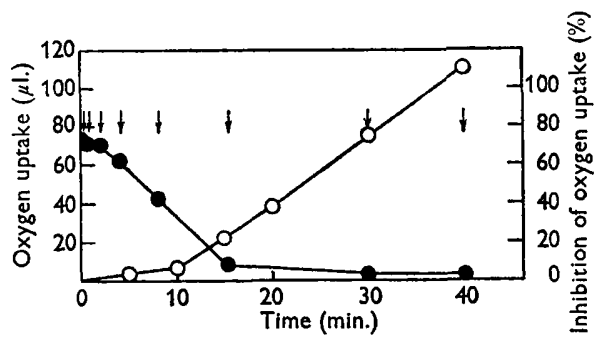

Fig. 4

Fig. 3. Effect of pre-incubation with glucose on the rate of oxidation of $\left.{ }^{14} \mathrm{C}\right)$ glutamate and incorporation of radioactivity into the bacterial cells. Each Warburg flask contained $50 \mathrm{~mm}$-tris buffer (pH 7.2), $15 \mathrm{mg}$. wet wt. washed bacteria and $3 \cdot 3 \mathrm{~mm}-\mathrm{KCl}$ or/and $3 \cdot 3$ mu-glucose when indicated. Total volume: $3 \cdot 0 \mathrm{ml}$. After $10 \mathrm{~min}$. pre-incubation at $28^{\circ}$ $10 \mu$ mole of $\left({ }^{14} \mathrm{C}\right.$ ) glutamate (specific activity $0.025 \mu \mathrm{c} / \mu \mathrm{mole}$ ) were added from the sidearm and the incubation was continued. The amount of $\left({ }^{14} \mathrm{C}\right) \mathrm{CO}_{2}$ liberated and of the radioactivity taken up by the bacteria was estimated as described under Methods. $\mathrm{O}, \boldsymbol{\ominus}, \square, \square,\left({ }^{14} \mathrm{C}\right) \mathrm{CO}_{2}$ production; $\triangle \Delta$, incorporation of radioactivity into the cells organism. Shaded marks: glucose added. In the experiments represented by the curves $\mathrm{O}$ and $\mathrm{OCl}$ was omitted from the reaction mixture.

Fig. 4. Time-dependence of the $m$-Cl-CCP-induced inhibition of glutamate oxidation. Each Warburg flask contained $50 \mathrm{~mm}$-tris buffer (pH 7.2), 3.3 mM-KCl, 3.3 mM-glutamate and $15 \mathrm{mg}$. wet wt. washed bactera. Total volume: $3 \cdot 0 \mathrm{ml}$. Incubation temperature: $28^{\circ}$. After various times of incubation $m$-Cl-CCP (to $1 \mu \mathrm{M}$ final concentration) was added from the side-arm to the respiring bacteria. $O$, Time-course of oxygen uptake; $\bullet$, $\%$ inhibition of respiration with $m$-Cl-CCP added at the times indicated by the arrows.

trasted with the prolonged lag of oxygen uptake displayed by the cells pre-incubated in the absence of glucose and which at the time of glutamate addition contained only $0.08 \mu$-equiv. $\mathrm{K}^{+} / 15 \mathrm{mg}$. wet wt. In contradistinction to the time-course of $\mathrm{CO}_{2}$ output the incorporation of radioactivity into the cell mass was practically unaffected by the omission of glucose (Fig. 3).

The above findings indicated therefore that the initial lag observed in the oxygen uptake by the $\mathrm{K}^{+}$-depleted organisms reflected the time required for the intracellular accumulation of $\mathrm{K}^{+}$.

\section{Effect of metabolic inhibitors}

The current notion that ion transport across biological membranes is an energydependent process suggested that blockage of the synthesis of ATP by suitable 
metabolic inhibitors might abolish the initial phase of $\mathrm{K}^{+}$accumulation and the apparently correlated increase in the respiration rate. Consequently, substances known for their ability to uncouple oxidative phosphorylations, such as 2,4dinitrophenol, methylene blue (Lehninger, 1949) and $m$-Cl-CCP (Heytler, 1963) were added at various stages of incubation and their effect on oxygen uptake was noted. While 2,4-dinitrophenol up to $0.3 \mathrm{~mm}$ showed no measurable effect on the respiration, methylene blue and $m$-Cl-CCP gave strong inhibition of glutamate oxidation when added at the start of incubation. The extent of this inhibitory effect, however, decreased in a striking fashion when the addition of the inhibitor was postponed for $\mathbf{3 0}$ min. following the onset of incubation, i.e. until the respiration has reached the steady-state value (Table 3 ).

The correlation between the time of addition of the inhibitor and its effect on the respiration was also studied in the kinetic experiment depicted in Fig. 4. As seen from the figure, the inhibition induced by $m$-Cl-CCP was inversely related to the rate of oxidation prevailing at the time of its addition.

\section{Table 3. Effect of inhibitors}

Each Warburg flask contained 50 mm-tris buffer (pH 7.2), 3.3 mm-glutamate, 3.3 mM$\mathrm{KCl}$ and washed $E$. coli (15 mg. wet wt.); total volume $3.0 \mathrm{ml}$. The inhibitors were added at the time indicated. Incubation was at $28^{\circ}$.

\begin{tabular}{|c|c|c|c|c|c|}
\hline \multirow[b]{2}{*}{ Inhibitor } & & \multicolumn{2}{|c|}{ Time of addition } & \multirow[b]{2}{*}{$\begin{array}{c}\text { Oxygen } \\
\text { uptake* } \\
(\mu \mathrm{l} / \mathrm{hr})\end{array}$} & \multirow[b]{2}{*}{$\begin{array}{c}\text { Inhibition } \\
(\%)\end{array}$} \\
\hline & & $\begin{array}{l}\text { Zero } \\
\text { time }\end{array}$ & $\begin{array}{l}30 \text { min. } \\
\text { after } \\
\text { substrate }\end{array}$ & & \\
\hline None & & - & - & 165 & None \\
\hline$m$-Cl-CCP & $1 \cdot 0 \mu \mathrm{M}$ & $\begin{array}{l}+ \\
-\end{array}$ & $\overline{+}$ & $\begin{array}{r}34 \\
170\end{array}$ & $\begin{array}{c}80 \\
\text { None }\end{array}$ \\
\hline & $0.5 \mu \mathrm{M}$ & + & $\overline{+}$ & $\begin{array}{r}75 \\
168\end{array}$ & $\begin{array}{c}65 \\
\text { None }\end{array}$ \\
\hline Methylene blue & $0.3 \mathrm{~mm}$ & + & $\overline{+}$ & $\begin{array}{r}20 \\
135\end{array}$ & $\begin{array}{l}88 \\
18\end{array}$ \\
\hline & $0.6 \mathrm{~mm}$ & + & $\overline{+}$ & $\begin{array}{l}15 \\
50\end{array}$ & $\begin{array}{l}91 \\
70\end{array}$ \\
\hline 2,4-Dinitrophenol & $0.3 \mathrm{~mm}$ & + & $\overline{+}$ & $\begin{array}{l}163 \\
168\end{array}$ & $\begin{array}{l}\text { None } \\
\text { None }\end{array}$ \\
\hline
\end{tabular}

* In the 60 min. following the addition of the inhibitor.

It has been previously reported that $m$-Cl-CCP inhibits the glucose-dependent respiration to a much lesser degree than the oxidation of other substrates (Avi-Dor, 1963). It was reasoned, therefore, that if $m$-Cl-CCP inhibits glutamate oxidation by interfering with the process of energy generation required for furthering the $\mathbf{K}^{+}$ transport, then addition of glucose would restore the normal rate of both $\mathrm{K}^{+}$ accumulation and glutamate oxidation. This prediction was fully borne out by the results presented in Table 4 .

\section{Effect of growth conditions}

In some experiments Escherichia coli was grown on the minimal medium of Davis \& Mingioli (1950) in which glucose was replaced by succinate or glutamate 
as a carbon source. As seen from Table 5, organisms grown on succinate oxidized glutamate at a lower rate than those which were grown on glutamate or on nutrient agar. Nevertheless, this difference in the rate of oxidation was not accompanied by a change in the dependence on potassium ion or an alteration in the pattern of response to $m$-Cl-CCP.

\section{Table 4. Abolition by glucose of $m$-Cl-CCP-induced inhibition of glutamate oxidation by Escherichia coli}

Each Warburg flask contained 50 mM-tris buffer (pH 7·2), 3.3 mM-KCl, 3.3 mM-glutamate containing $0.025 \mu \mathrm{c}$. uniformly labelled $\left({ }^{14} \mathrm{C}\right)$ glutamate, $15 \mathrm{mg}$. wet wt. washed bacteria and where indicated, $3 \cdot 3 \mathrm{~mm}$-glucose and $1 \mu \mathrm{M} m$-Cl-CCP. Total volume 3.0 ml. Oxidation of glutamate is expressed in terms of $\left.{ }^{14} \mathrm{C}\right) \mathrm{CO}_{2}$ evolution. Incubation: 60 min. at $28^{\circ}$. The $\mathrm{K}^{+}$content determined at the start of incubation was $0.08 \mu$-equiv. $/ 15 \mathrm{mg}$. bacterial wet wt.

Additions to the basal reaction mixture

$m$-Cl-CCP
None (control)
+
None
+

Glucose
None
None
+
+

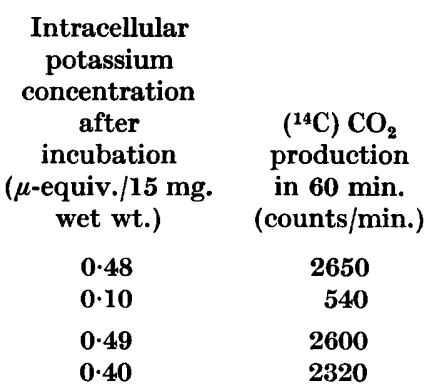

Table 5. Identical patterns of response to $\mathrm{K}^{+}$and $\mathrm{m}$-Cl-CCP of Escherichia coli cells grown on various media

The growth conditions were as described under Methods. Each Warburg flask contained $50 \mathrm{~mm}$-tris chloride (pH 7.2), 3.3 mM-KCl, 3.3 mm-glutamate and $15 \mathrm{mg}$. wet wt. of Escherichia coli cell, grown on the various solid media indicated in the Table. Total volume: $3 \mathrm{ml}$. 'Lag' denotes the time required for attainment of a constant rate of oxygen uptake.

Growth medium

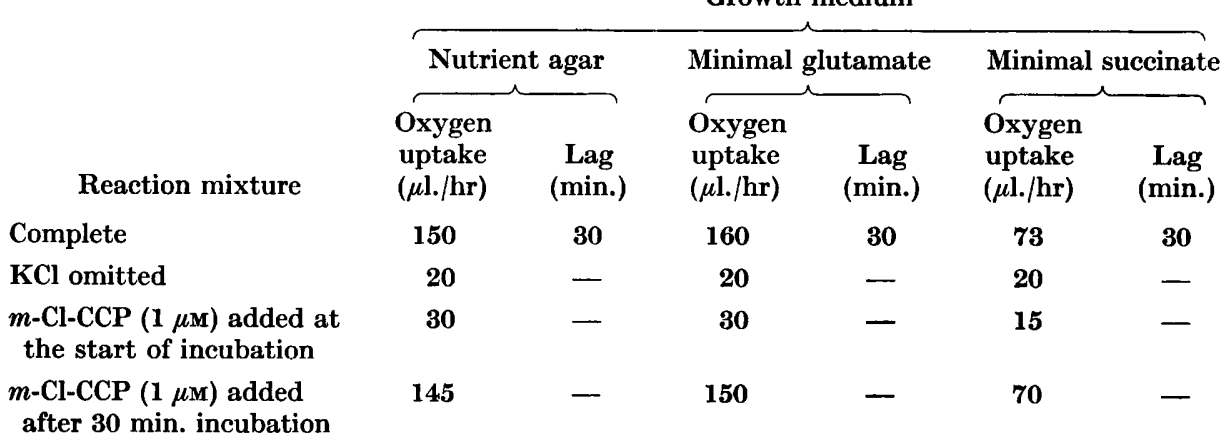

\section{DISCUSSION}

Respiratory and glycolytic energy is known to drive ion uptake and accumulation in various biological systems (see Rothstein, 1959; Robertson, 1960). The converse situation is that the rate of respiration is determined by the rate of active transport. Anion transport is thought to regulate respiration in plants (Lundegaardh, 1954) and the respiratory activity of brain slices seems to depend on the flux of sodium and 
potassium ions (Whittam, 1961). Oxidative processes in tightly coupled systems are governed by the availability of ADP and inorganic phosphate (Lardy \& Wellman, 1952) and an ATP-splitting mechanism appears to underly the transport of potassium and sodium across biological membranes (see Hokin \& Hokin, 1963).

The results of the present kinetic studies indicate that the rate of glutamate oxidation in Escherichia coli is determined by the intracellular concentration of $\mathrm{K}^{+}$ rather than by the flux of this ion. This conclusion is also supported by the characteristic pattern of respiratory inhibition induced by methylene blue and even more strikingly by $m$-Cl-CPP, a potent uncoupling agent of oxidative phosphorylation recently described by Heytler (1963). These compounds interfered with glutamate oxidation only when added in the initial phase of incubation, i.e. before a sufficient pool of $\mathrm{K}^{+}$accumulated in the organism. Assuming that the $m$-Cl-CCP action in bacteria is also attributable to inhibition of oxidative phosphorylation (see AviDor, 1963), the following explanation seems to account for the above observation. The accumulation of $\mathrm{K}^{+}$which takes place in the depleted bacteria during the lagphase of glutamate oxidation requires that the limited amount of energy generated by the initial low rate of glutamate oxidation should be entirely available for ATP synthesis. Therefore, uncoupling of oxidative phosphorylation by eliminating the major source of ATP supply inhibits both $\mathrm{K}^{+}$transport and the potassium-dependent oxidation of glutamate; the resulting vicious circle will ultimately lead to the complete interruption of the two interdependent processes. On the other hand, once the requisite amount of $\mathrm{K}^{+}$has accumulated in the bacteria, the substrate-level phosphorylation (which is presumably insensitive to the blocking effect of $m$-Cl-CCP and methylene blue) may be adequate to meet the energy requirement of the system for maintaining a constant level of intracellular $\mathrm{K}^{+}$. This interpretation is also in line with the observation that the $m$-Cl-CCP inhibition was largely abolished by adding glucose, presumably owing to the capacity of the latter substrate to insure a copious supply of ATP via the glycolytic pathway. It is noteworthy that depletion of intracellular $\mathrm{K}^{+}$which resulted in a practically complete suppression of glutamate oxidation did not impair the rate of succinate oxidation. Since succinoxidase is a particle-bound enzyme in Escherichia coli (Hughes, 1962; Kashket \& Brodie, 1963) it would be of interest to see whether the lower potassium requirement is a distinctive feature shared also by other particulate oxidative enzymes.

This work was done in partial fulfilment of the requirements for a $\mathrm{Ph} . \mathrm{D}$. of the Hebrew University, Jerusalem. We are indebted to Miss T. Sari for able technical assistance.

\section{REFERENCES}

Avi-Dor, Y. (1963). Inhibition of the respiration of $E$. coli by carbonyl cyanide $m$ chlorophenylhydrazone. Acta chem. scand. 17, 144.

Bray, G. A. (1960). A simple efficient liquid scintillator for counting aqueous solutions in a liquid scintillation counter. Analyt. Biochem. 1, 279.

Buhler, D. R. (1962). A simple scintillation counting technique for assaying ${ }^{14} \mathrm{CO}_{2}$ in a Warburg flask. Analyt. Biochem. 4, 413.

Davis, B. D. \& MingrouI, E. S. (1950). Mutants of E. coli requiring methionine or vitamin B $_{12}$. J. Bact. 60, 17.

Hems, R. \& KReBs, H. A. (1962). Further experiments on the potassium uptake by Alcaligenes faecalis. Biochem. J. 82, 80. 
Heytler, P. G. (1963). Uncoupling of oxidative phosphorylation by carbonyl cyanide phenylhydrazons. Biochemistry, 2, 357.

Hokın, L. E. \& Hokin, M. R. (1963). Biological transport. A. Rev. Biochem. 32, 553.

Hughes, D. E. (1962). The bacterial cytoplasmic membrane. J. gen. Microbiol. 29, 39.

KashKeT, E. R. \& Brodie, A. F. (1963). Oxidative phosphorylation in fractionated bacterial systems. VIII. Role of particulate and soluble fractions from Escherichia coli. Biochim. biophys. Acta, 78, 52.

Krebs, H. A., Whittam, R. \& Hems, R. (1957). Potassium uptake by Alcaligenes faecalis. Biochem. J. 66, 53.

LARDY, H. A. \& Wellman, H. (1952). Oxidative phosphorylation. Role of inorganic phosphate and acceptor systems in control of metabolic rates. J. biol. Chem. 195, 215.

LEHNinger, A. L. (1949). Esterification of inorganic phosphate coupled to electron transport between dihydrodiphosphopyridine nucleotide and oxygen. J. biol. Chem. 178, 625.

LundegaARDh, H. (1954). Anion respiration. Symp. Soc. exp. Biol. 8, 262.

Miller, S. \& Avi-Dor, Y. (1958). The effect of inorganic ions on respiration in $P$. tularensis and E. coli. J. gen. Microbiol. 18, 221.

Quastel, J. H. \& WeBleY, D. M. (1942). Vitamin $B_{1}$ and bacterial oxidation. II. The effects of magnesium, potassium and hexose diphosphate ions. Biochem. J. 36, 8.

Robertson, R. N. (1960). Ion transport and respiration. Biol. Rev. 35, 231.

Rothstein, A. (1959). Role of the cell membrane in the metabolism of inorganic electrolytes by micro-organisms. Bact. Rev. 23, 175.

Whitram, R. (1961). Active carbon transport as a pace-maker of respiration. Nature, Lond. 191, 604. 